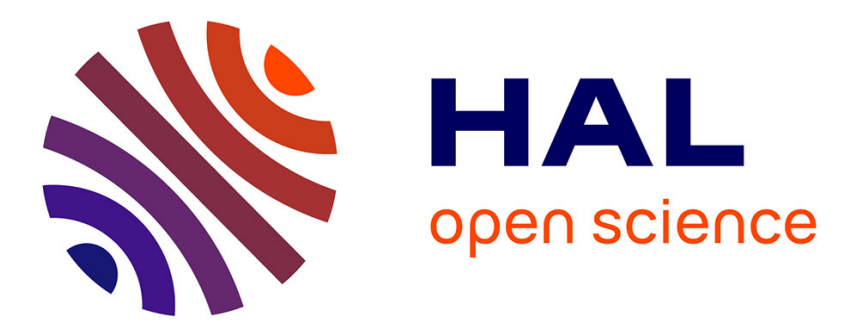

\title{
In situ TEM study of dislocation slip in a metastable $\beta$ titanium alloy
}

\author{
Philippe Castany, M. Besse, Thierry Gloriant
}

\section{To cite this version:}

Philippe Castany, M. Besse, Thierry Gloriant. In situ TEM study of dislocation slip in a metastable $\beta$ titanium alloy. Scripta Materialia, 2012, 66 (6), pp.371-373. 10.1016/j.scriptamat.2011.11.036 . hal-00864935

\section{HAL Id: hal-00864935 \\ https://hal.science/hal-00864935}

Submitted on 23 Sep 2013

HAL is a multi-disciplinary open access archive for the deposit and dissemination of scientific research documents, whether they are published or not. The documents may come from teaching and research institutions in France or abroad, or from public or private research centers.
L'archive ouverte pluridisciplinaire HAL, est destinée au dépôt et à la diffusion de documents scientifiques de niveau recherche, publiés ou non, émanant des établissements d'enseignement et de recherche français ou étrangers, des laboratoires publics ou privés. 


\title{
In situ TEM study of dislocation slip in a metastable $\beta$ titanium alloy
}

\author{
P. Castany ${ }^{*}$, M. Besse, T. Gloriant \\ INSA de Rennes, UMR CNRS 6226 Sciences Chimiques de Rennes/Chimie-Métallurgie, 20 \\ avenue des Buttes de Coësmes, CS70839, 35708 Rennes Cedex 7, France
}

\begin{abstract}
Dislocation slip is investigated in a metastable $\beta$ titanium alloy with the Ti-23Nb-0.7Ta-2Zr$0.4 \mathrm{Si}$ composition (at. \%) by in situ straining experiments in a transmission electron microscope (TEM). Moving dislocations have $a / 2<111>$ Burgers vectors and glide in $\{110\}$, $\{112\}$ or $\{123\}$ planes. The mobility of screw dislocations is lowered by punctual defects and the existence of a stable and sessile core configuration that has to recombine in order to allow dislocations to glide.
\end{abstract}

Keywords: Titanium alloys; Transmission electron microscopy (TEM); Dislocations; In situ straining; Slip

In metastable $\beta$ titanium alloys, the deformation is known to be accommodated by several mechanisms such as a stress-induced martensitic transformation, twinning or dislocation slip. Because shape memory and superelastic properties can be obtained from this phase transformation, stress-induced martensitic transformation is widely studied in metastable $\beta$

\footnotetext{
* Corresponding author.

E-mail address: philippe.castany@insa-rennes.fr
} 
titanium alloys [1-4]. Occurrence of two twinning systems was also reported and investigated [5-8], but no clear data on dislocation slip and dislocation mobility are available in the literature. The only study reporting results on the dislocation mobility in a metastable $\beta$ titanium alloy was carried out recently in a TNTZO "Gum Metal" alloy $[9,10]$. In this letter, in situ straining experiments in a transmission electron microscope (TEM) were performed to investigate dislocation slip in a Ti-Nb-Zr-Ta based alloy with Si addition (TNTZSi). Results are discussed and compared with TNTZO in order to determine the different effects of addition of $\mathrm{O}$ and $\mathrm{Si}$ on the dislocation mobility.

The metastable $\beta$ titanium alloy with the composition Ti-23Nb-0.7Ta-2Zr-0.4Si (at. \%) was elaborated by cold crucible levitation melting (CCLM) of pure raw materials. Ingots were next homogenized at $1223 \mathrm{~K}$ during 16 hours, 90\% cold rolled, recrystallized at $1143 \mathrm{~K}$ during 0.5 hour and water quenched. The as-quenched microstructure consists of equiaxed grains of $\beta$ phase (bcc structure) with an average size of $20 \mu \mathrm{m}$.

In situ straining experiments were performed at room temperature in a JEOL 2010 TEM operating at $200 \mathrm{kV}$ and using a Gatan straining holder. In situ observations were recorded with a SIS CCD camera for video rate recording. Dimensions of micro tensile specimens are $9 \mathrm{~mm} \times 2.3 \mathrm{~mm} \times 80 \mu \mathrm{m}$ (Fig. 1). They were thinned down in the centre of the reduced section using a twin-jet electropolishing system with a solution of $6 \%$ perchloric acid, $59 \%$ methanol and 35\% 2-butoxyethanol (vol.\%). Burgers vectors of dislocations were determined by regular indexation using the invisibility criterion.

During in situ straining, all moving dislocations observed have $a / 2<111>$ Burgers vectors. Slip planes are determined to be $\{110\},\{112\}$ or $\{123\}$ planes from slip trace analysis. At least two different slip systems are usually activated simultaneously in the same grain. These 
slip systems are those commonly observed in bcc metals. An example is shown in Fig. 2: a dislocation, labelled A, moves and leaves a slip trace at the surface of the specimen (Fig. 2 a and b). In Fig. 2c, this dislocation cross-slips. The analysis of the orientation of both traces shows that the dislocation first glides in the (321) plane and cross-slip in the (110) plane (directions of intersections of both planes with the surface of the specimen are indicated in Fig. 2d). The preferential slip plane is (110), indeed all dislocations observed cross-slip in this plane and do not cross-slip back to the (321) plane. Several dislocations cross-slip in the same way but all these dislocations were first present in the grain before straining as the dislocation labelled B. During straining, they glide first in this (321) plane because they lie in this plane before and cross-slip next in the (110) plane. It is also worth noting that all dislocations of the Fig. 2 have the same Burgers vector and that moving dislocations have a screw character (the projection of the Burgers vector direction is indicated as $\mathbf{b}$ in Fig. 2a). However, some dislocations have not a screw character (as the one labelled B). Some moving dislocations, like the dislocation labelled $\mathrm{A}$, have first the same character as the dislocation $\mathrm{B}$ before straining. But during straining, non-screw segments move quickly out of the specimen and the further propagation is thus only due to screw segments.

A frame-by-frame analysis of the Fig. 2 shows that the dislocation labelled A jumps first across a long distance (Fig. 2a to 2b). This jump is as fast as one video frame, i.e. 0.04s. Next, from Fig. $2 \mathrm{~b}$ to $2 \mathrm{c}$ and further, the motion seems alternatively steadier or composed of fast jumps (see moviel as supplementary material). In order to analyse more precisely the motion of screw dislocations, weak beam dark field conditions were also used during straining. An example of the motion of a $a / 2<111>$ screw dislocation gliding in a $\{112\}$ plane is shown in Fig.3. Between each frame of the Fig. 3, the dislocation remains immobile and moves during a time shorter than a video frame $(0.04 \mathrm{~s})$ from its previous position, indicated by a dashed line, to its new position (see also the movie 2 as supplementary material). The motion is also 
composed of short jumps of small parts of the screw dislocation leading to an apparent steadier motion at lower magnification as in Fig. 2. In pure bec metals, it was commonly observed that the whole screw dislocation jumps from a position to another one [11-13] but a motion composed of jumps of successive parts was already observed in a TNTZO $\beta$ titanium alloy with similar composition $[9,10]$. In this previous study, the motion by successive parts was attributed to pinning points due to atom clusters containing oxygen but these pinning points had not a detrimental effect on the mobility of screw dislocations as dislocations were not pinned on each punctual defect they swept and made long jumps. In the present study, the motion is quite different because the moving parts of screw dislocations as well as the length of the jump are very short. This suggests that dislocations are pinned on each punctual defect and that these pinning points have a non-negligible effect on the motion of screw dislocations in the TNTZSi investigated alloy. Such pinning points are indicated by dark arrows in Fig. 3 and are most probably due to Si atoms or clusters.

In TNTZO titanium alloy, it was shown that the motion of screw dislocations is composed of successive fast jumps at room temperature $[9,10]$. In pure bcc metals, a steady motion was observed at room temperature whereas the motion is jerky at lower temperature [11-13]. The steady motion is commonly attributed to a kink-pair mechanism $[11,12,14]$ and the jerky motion to the transition between two core configurations of screw dislocations from a threedimensionally spread and sessile core structure to a glissile core structure $[9,13,15,16]$. The temperature of transition between these two mechanisms is below room temperature in pure bcc [11-13]. In the TNTZSi alloy investigated, the jerky motion is observed at room temperature indicating that the transition between the two core configurations is the mechanism controlling the mobility of screw dislocations. This observation is in agreement with previous observations in TNTZO alloy $[9,10]$. However, in TNTZO the stress needed to overcome the barrier between the two core configurations is larger than the stress needed to 
overcome punctual defects leading to a negligible effect of punctual defects on the mobility of dislocations. Contrarily, in the TNTZSi investigated alloy, the stress needed to overcome punctual defects seems to have a similar value in comparison with the stress needed to the transition between the two core structures. The mobility of screw dislocations is thus controlled by their core structure and the presence of punctual defects leading to a jerky motion but with very short jumps due to the pinning on punctual defects. Addition of Si decreases thus the reduction in energy of screw dislocations due to their core structure and increases the strength of punctual defects as obstacles to dislocation motion in comparison with $\mathrm{O}$ addition. The strengthening effect of Si seems so to be mainly due to punctual defects whereas the strengthening effect of $\mathrm{O}$ is due to an important decrease in energy of the core structure of screw dislocations. It is also worth noting that the motion of non-screw segments is not impeded by punctual defects as in TNTZO alloy leading to a deformation carried mainly by long screw segments.

The Fig. 3 shows also the multiplication of another dislocation that is creating a dislocation loop (labelled L in Fig. 3) by a well-known mechanism due to multiple cross-slips $[10,11,15]$. This mechanism occurs not as extensively as in TNTZO alloy [10] leading to a slightly more homogeneous deformation (Fig. 2).

As a summary, dislocations with $a / 2<111>$ Burgers vectors are observed to glide in $\{110\}$, $\{112\}$ or $\{123\}$ planes in a metastable $\beta$ titanium alloy. The deformation is carried by long screw segments because of their lower mobility than non-screw segments. This low mobility is due to an in-core rearrangement as well as the presence of punctual defects that both impede the motion of screw segments. With addition of $\mathrm{Si}$, the strengthening effect of punctual defects as obstacles to dislocation motion appears to be more important in 
comparison with $\mathrm{O}$ addition for which the strengthening effect is due to a decrease in energy of core structure of screw dislocations.

The authors acknowledge financial support from the French CNRS and CEA METSA network for in situ TEM experiments.

[1] H.Y. Kim, Y. Ikehara, J.I. Kim, H. Hosoda, S. Miyazaki, Acta Mater. 54 (2006) 2419.

[2] Y.L. Hao, S.J. Li, S.Y. Sun, C.Y. Zheng, R. Yang, Acta Biomater. 3 (2007) 277.

[3] M. Tahara, H.Y. Kim, H. Hosoda, S. Miyazaki, Acta Mater. 57 (2009) 2461.

[4] T. Inamura, Y. Yamamoto, H. Hosoda, H.Y. Kim, S. Miyazaki, Acta Mater. 58 (2010) 2535.

[5] M. Oka, Y. Taniguchi, Metall. Mater. Trans. A 10 (1979) 651.

[6] S. Hanada, O. Izumi, Metall. Trans. A 17 (1986) 1409.

[7] X.H. Min, S. Emura, T. Nishimura, L. Zhang, S. Tamilselvi, K. Tsuchiya, K. Tsuzaki, Mater. Sci. Eng. A 527 (2010) 1480.

[8] E. Bertrand, P. Castany, I. Péron, T. Gloriant, Scripta Mater. 64 (2011) 1110.

[9] P. Castany, M. Besse, T. Gloriant, Phys. Rev. B 84 (2011) 020201.

[10] M. Besse, P. Castany, T. Gloriant, Acta Mater. 59 (2011) 5982.

[11] E. Furubayashi, J. Phys. Soc. Jpn. 27 (1969) 130.

[12] F. Louchet, L.P. Kubin, D. Vesely, Philos. Mag. A 39 (1979) 433.

[13] D. Caillard, Acta Mater. 58 (2010) 3504.

[14] D. Caillard, Acta Mater. 58 (2010) 3493.

[15] P. Castany, F. Pettinari-Sturmel, J. Crestou, J. Douin, A. Coujou, Acta Mater. 55 (2007) 6284.

[16] S. Farenc, D. Caillard, A. Couret, Acta Metal. Mater. 43 (1995) 3669. 


\section{Figure 1}

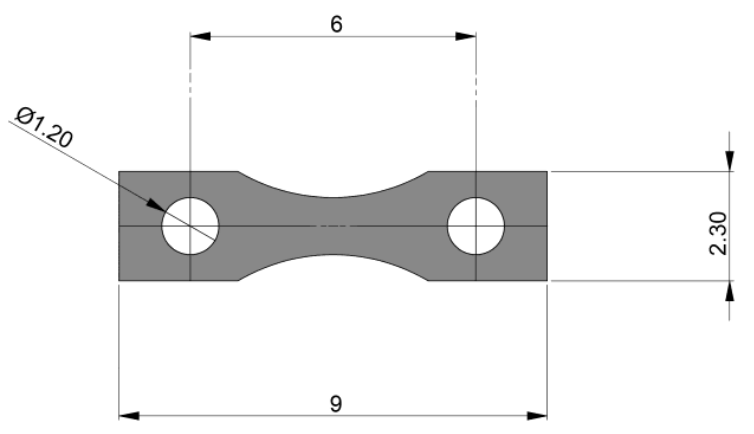

Figure 1. Dimensions of micro tensile specimens for in situ TEM experiments. 

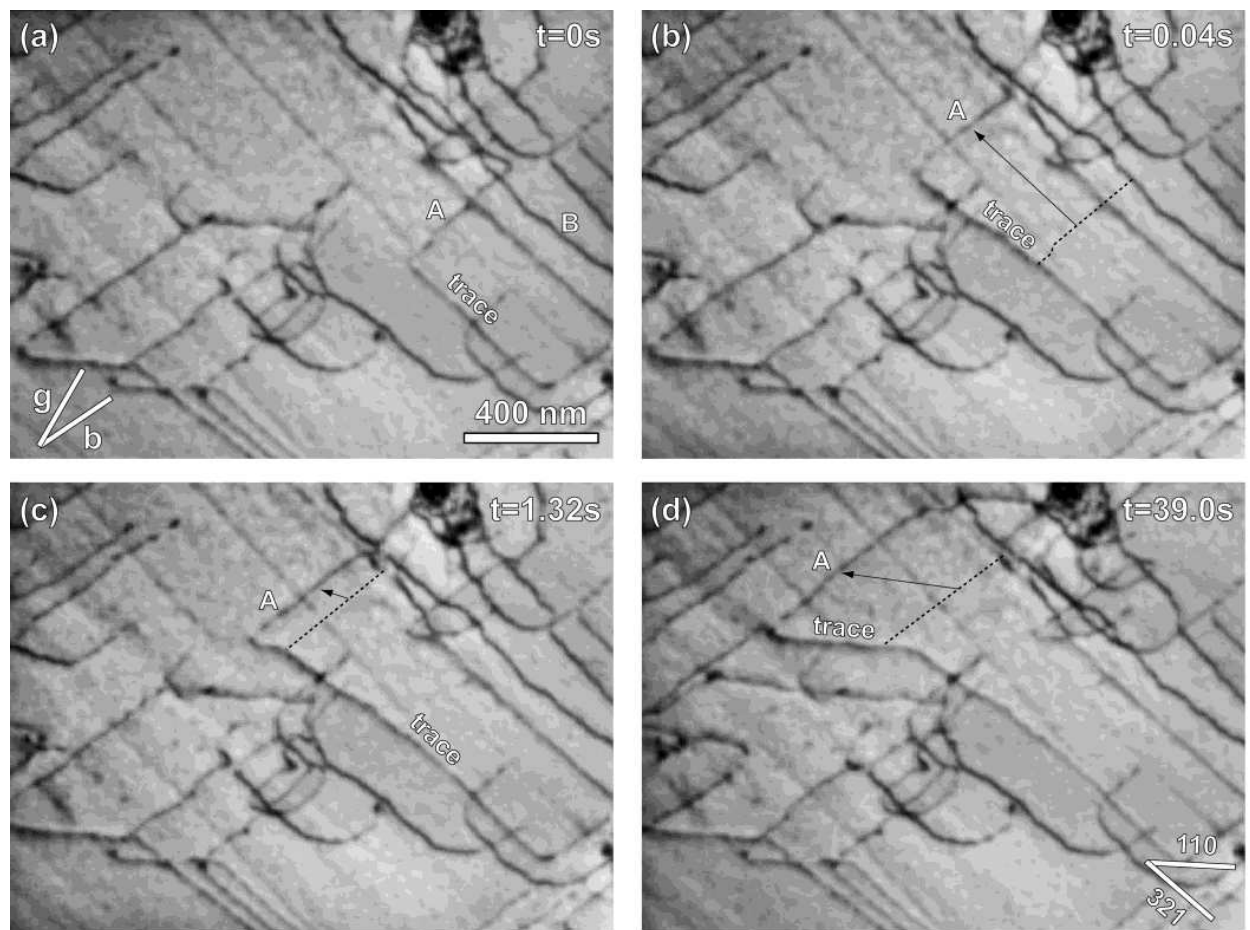

Figure 2. Motion of screw dislocations during in situ TEM straining; the dislocation labelled A cross-slip from (321) plane to (110) plane; a dashed line indicates the previous position of the dislocation A on each frame. 


\section{Figure 3}
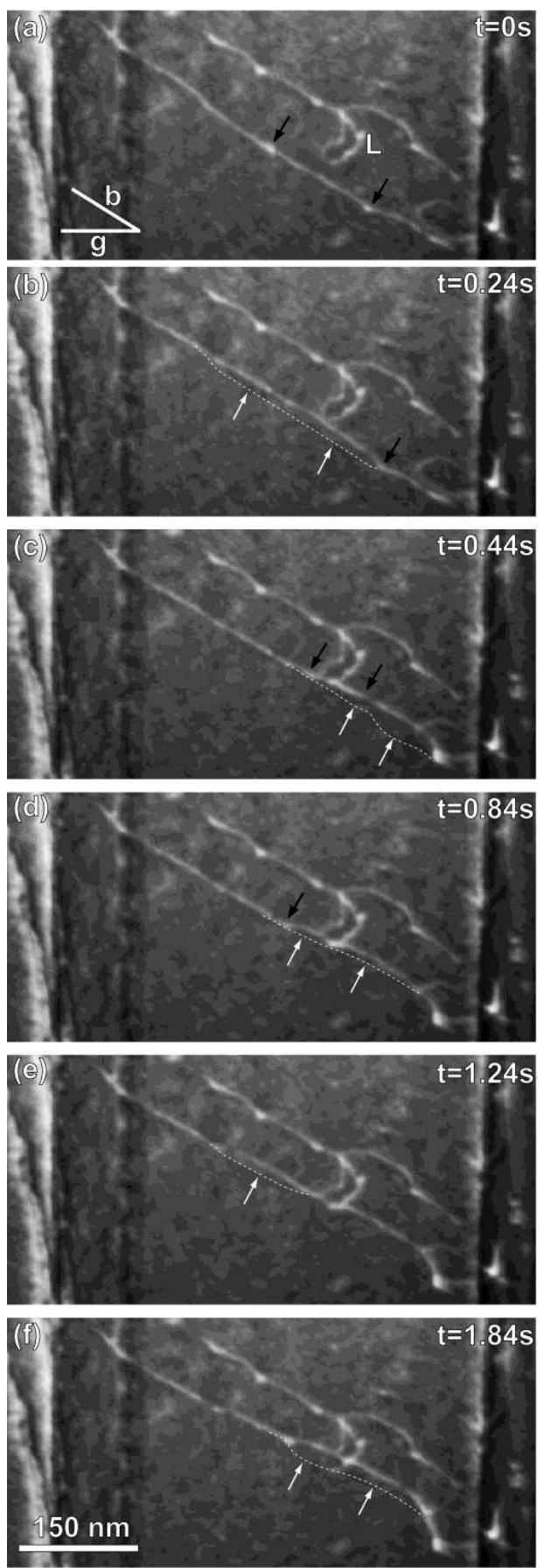

Figure 3. Weak beam dark field micrographs of screw dislocations gliding in a $\{112\}$ plane taken during in situ TEM straining; a dashed line indicates the previous position of the moving dislocation on each frame. 
Supplementary Material Movie1

Click here to download Supplementary Material: Movie1.mov 
Supplementary Material Movie2

Click here to download Supplementary Material: Movie2.mov 